\title{
Investigation and research on railway passenger car and EMU battery
}

\author{
Yuan Wen
}

North China Electric Power University, Baoding, Hebei, China

Keywords: railway passenger car; battery; lithium ion battery technology scheme

\begin{abstract}
China railway passenger cars from 25B green cars to the development of high speed EMU, the battery is still followed the lead-acid battery and cadmium nickel battery, battery containing heavy metal railway passenger cars will bring great harm to the environment. Through access to a large number of data and field survey, compared the performance of various types of battery, analyzes the feasibility of railway passenger cars and high-speed EMU application of lithium ion batteries, and developed a technique scheme of lithium ion battery.
\end{abstract}

\section{Introduction}

The rapid development China railway, from the early without air conditioning "green cars" to electric locomotive traction air conditioning bus to high speed EMU now, not only the operation speed is increased from $120 \mathrm{Km} / \mathrm{h}$ to $350 \mathrm{Km} / \mathrm{h}$, comfort, stability, safety is improved greatly. But, whether ordinary passenger cars or high speed EMU, auxiliary power supply and battery using emergency power supply are lead-acid batteries or nickel cadmium alkaline batteries, not progress along with the rapid development of passenger car equipment, lead-acid batteries and nickel cadmium batteries have a common problem - battery contains lead, cadmium and other heavy metals to the environment cause serious pollution.

Our country has not established a sound waste battery recycling system, has not been able to a professional, batch processing of waste battery business ,because of the railway network throughout the country, the large number of railway passenger car, deal with problems of railway passenger car batteries has become a difficult problem. Looking for a kind of environmental protection battery can replace the railway passenger car $\mathrm{Cd} \mathrm{Ni}$ alkaline battery has become a pressing matter of the moment, to Protect environment, saving resources of great significance.

\section{The railway passenger car battery application investigation}

\subsection{The old railway passenger car}

The early railway passenger car only light and fan, bus run by generators installed on the axle, passenger station, by lead or cadmium nickel storage battery power supply. The generator and battery in parallel to the car for all the lights and fan power supply, lead-acid battery model TG350, TG450, TG54, alkaline cadmium

Nickel battery model GN300[1].

\subsection{DC600V railway passenger car}

Power supply railway passenger car electric locomotive with electric locomotive traction, electric locomotive through the roof of the pantograph and contact elevated to obtain power grid. The railway passenger car electric equipment such as air conditioning, lights and sockets, the control system also consists of electric locomotive power supply. Because the electric railway at intervals of $50 \mathrm{~km}$ or so there is a non electricity zone, when the train enters the non electricity zone, to ensure the passenger car lighting and control system for uninterrupted power supply, each passenger car battery to supply the power to set the lighting and control systems, battery powered passenger electric locomotive is 110 Volts 120 when nickel cadmium alkaline battery.

The battery box of cadmium nickel alkaline battery installed in the under of passenger car, each passenger car installed with two battery box. Two battery box number 78batteries, battery 
weight $546 \mathrm{~kg}$, battery and battery box weighing about $946 \mathrm{~kg}$.

\subsection{High speed EMU}

Modern high speed EMU railway transportation equipment is the most advanced, and similar electric locomotive power supply bus, EMU control and lighting and so on 110V DC power supply, during normal operation, the EMU auxiliary converter through the charger for EMU EMU DC110V power supply, in the garage or power grid fault condition, the battery as the power supply equipment of DC power supply, to ensure the power supply to the control of EMU, lighting, battery 110 V 320 ampere hour cadmium nickel alkaline battery.

The battery box of cadmium nickel alkaline battery installed in the under of passenger car, each passenger car provided with a storage battery box. A total of 168batteries, battery weight 1184 $\mathrm{kg}$, battery and battery box weighing about 1.8 tons.

\section{The 2 railway passenger waste battery treatment investigation}

China's current lack of electronic waste management of waste batteries and other specific policies and regulations, scrap battery mostly without recycling, but at the disposal of, a potential threat to the ecological, environmental and public health, also makes a lot of reusable resources are not utilized, resulting in the waste of scarce resources.

Railway network throughout the country, in a considerable number of area, used batteries are long delayed, without appropriate processing conditions. Although recycling lead-acid battery manufacturers currently have, in fact just transfer problems, did not solve the problem, the alkaline battery has not recycling capacity, most are piled up in the open air in the country.

\subsection{Qingdao depot survey}

The Qingdao depot battery workshop to understand, every cell processing occupies a lot of space, in which each maintenance workshop are separately two, specialized treatment of acid and alkaline batteries (two batteries need to strictly separate). The accumulation of a large number of waste battery ground. The alkaline battery 3000 are in the queue handling, low efficiency.

Qingdao depot scrap acid alkali cell dumps, not be appropriate treatment, and days and months multiplying more and more.

\subsection{Urumqi depot survey}

Urumqi depot scrap acid alkali cell dumps, serious environmental pollution. Unable to properly, will only cause the environment is getting worse.

\section{Harm waste battery}

\subsection{Lead-acid batteries harm}

Recycling scrapped lead-acid battery is not easy, once the lead-acid battery waste are casually discarded, resulting in lead acid liquid leakage, pollution of soil and water and into the human blood, the high content of Pb lead poisoning occurs, it will cause a series of abnormal manifestations of nervous system, blood system, digestive system of human body, serious or even life-threatening, particularly serious impact on children.

\subsection{Nickel cadmium batteries harm}

Cadmium nickel battery (Cd-Ni) cells using cadmium as electrode, cadmium is a toxic metal, human long-term chronic exposure to cadmium can cause kidney and bone injury, inhalation of cadmium dust may also damage the lungs.

\section{Railway passenger car battery application suggestion and scheme}

Lithium ion battery is a new energy battery in twentieth Century successfully developed. Lithium ion battery by the industry's favor because of high specific energy, small volume, no maintenance, environmental friendly gradually from the application of mobile 
phone, notebook computer to electric bicycles, electric cars and other large applications[4]. With the advancement of technology and the development of new energy industry, large capacity lithium ion battery technology and industry development is very fast, has become the mainstream of international large capacity battery, it is recommended to use lithium ion battery on railway passenger cars[2].

\subsection{Advantages of railway passenger cars and high-speed EMU application of lithium ion battery}

\subsubsection{Light weight}

The ordinary railway passenger car application of lithium ion battery, the weight ratio of rate Cd Ni alkaline battery weight $2 / 3$, ordinary railway passenger cadmium nickel alkaline battery weight of $546 \mathrm{Kg}$, the application of lithium ion batteries to reduce $372 \mathrm{Kg}$, if considered to reduce a battery box weight $200 \mathrm{Kg}$, the total weight can be reduced by $572 \mathrm{Kg}$, the mean energy consumption reducing weight reduce and material saving.

High speed EMU battery weight is $1184 \mathrm{Kg}$, the high speed EMU if the application of lithium ion battery, the weight can be reduced by $2 / 3790 \mathrm{Kg}$ can reduce.

Now the high-speed EMU battery cumbersome installation under a car battery box, if the application of lithium ion battery, the battery can be installed in the light of the cabinet, battery cabinet can also be placed in the car, thereby reducing weight and beauty.

\subsubsection{Security and maintainability}

Nickel cadmium battery charge and discharge process of electrochemical reaction will release hydrogen and oxygen, need of forced ventilation and natural ventilation, not suitable for indoor, car and other confined space use lithium ion battery without the use of gas generated in the process, can be used for any occasion[3].

The need for frequent maintenance nickel cadmium batteries in use process regular add distilled water, lithium ion batteries do not need regular maintenance.

\subsection{Application of high speed EMU lithium ion battery program}

\subsubsection{Design of lithium ion battery}

The existing high-speed EMU battery 110 V 320 Ah Ni Cdalkaline batteries, in order to guarantee the power supply performance, lithium ion battery group also need to use $110 \mathrm{~V} 320$ $\mathrm{Ah}[5]$.

With data access by lithium ion battery battery manufacturer, for convenient installation and combination, high power lithium ion battery generally integrated into the battery module, battery module voltage is $25.6 \mathrm{~V}$, the capacity is $40 \mathrm{Ah}$. According to series parallel principle, $110 \mathrm{~V} \quad$ voltage requires $\quad 4$ group $25.6 \quad$ V series parallel battery module, battery module 320 ampere hour capacity of the battery pack need 8 group 40Ah, circuit diagram of figure 1.

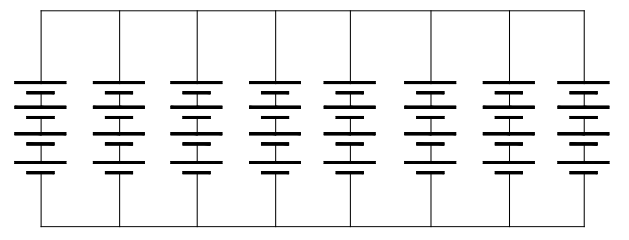

Fig. 1320 Ah battery Circuit diagram

\subsubsection{Battery charger adjustment}

In order to adapt to the charge characteristics of the existing high-speed EMU, rechargeable lithium ion battery group must match with the existing high speed EMU charger. Moderate cadmium nickel alkaline storage battery charging is divided into two stages: constant current charging -- floating charge. First of all, using the maximum charging current of 96 A to charge the battery voltage reaches U1, kept on U1 constant, the charging current is reduced, the current is reduced to below $13 \mathrm{~A}$, state of charge into 
the floating voltage from U1 to U2 constant voltage charging.

$\mathrm{U} 1=137,50 \mathrm{~V}---126,42 \mathrm{~V}$ ) adjustable

$\mathrm{U} 2=137,50 \mathrm{~V} . . .114,24 \mathrm{~V}$ ) adjustable

Lithium ion battery charging is divided into constant current mode boost charge - float in two stages, with $0.2 \mathrm{C}(64 \mathrm{~A})$ is charged to $118 \mathrm{~V}$, voltage of 118 volts and constant pressure charging. This charging method and charging method of rate $\mathrm{Cd} \mathrm{Ni}$ alkaline battery is basically the same, by means of adjusting the existing parameters of high speed EMU charger can realize charging to lithium ion battery.

\section{Summary}

(1) heavy metals, lead acid battery, nickel cadmium alkaline batteries contain will bring environment great pollution, harm people's health, in railway passenger suggestions of gradually reducing the use of.

(2) lithium ion battery as a "clean energy", has been successfully applied to various fields of modern life, suggestions on railway passenger cars and high-speed EMU application of lithium ion battery.

(3) the use of lithium ion battery, not only environmental protection, but also has small volume and light weight, especially for railway passenger car is very advantageous for high speed EMU weight loss.

(4) lithium ion battery discharge performance is good, especially suitable for the use of high speed EMU.

\section{Reference}

[1] Hu Xinguo, VRLA battery and its application in railway system [J], battery,2000.04

[2] Guo Binghun, et al. The lithium ion battery[M], Changsha: Central South University press, 2002.04.

[3] Tang Zhiyuan, Chen Yuhong, et al. Study on the safety of lithium-ionbattery[J], 2006, 36 (1):7.

[4] Hao Deli, Feng Xikang, Wang Boliang, et al. Study on lithium ion battery for electric vehicle power technology[J].Surgery, 2003, 27 (supp.).

[5] Yuan Fengbiao, research on the application of lithium ion battery on railway passenger cars[J], the locomotive electric transmission, 2011.03 